\title{
BCR translocation to derivative chromosome 2: A new case of chronic myeloid leukemia with a complex variant translocation and Philadelphia chromosome
}

\author{
WALID AL-ACHKAR, ABDULSAMAD WAFA and SUHER ALMEDANI \\ Molecular Biology and Biotechnology Department, Human Genetics Division, \\ Atomic Energy Commission of Syria, Damascus, Syria
}

Received November 19, 2009; Accepted February 23, 2010

DOI: 10.3892/ol_00000078

\begin{abstract}
The well-known typical fusion gene BCR/ABL is observed in connection with a complex translocation event in $5-8 \%$ of cases of chronic myeloid leukemia (CML). The present study described an exceptional CML case with complex chromosomal aberrations not previously observed. Aberrations included a translocated BCR to the derivative chromosome 2 [der(2)] that also involved a four-chromosome translocation, implying chromosomal regions $1 \mathrm{p} 32$ and $2 \mathrm{q} 21$, besides $9 \mathrm{q} 34$ and 22q11.2, which were characterized by molecular cytogenetics.
\end{abstract}

\section{Introduction}

Chronic myeloid leukemia (CML) is a clonal malignant disorder of pluripotent hematopoetic stem cells progressing from a chronic to an accelerated to a blast phase (1). The cytogenetic hallmark of CML is the Philadelphia $(\mathrm{Ph})$ chromosome, resulting from $\mathrm{t}(9 ; 22)(\mathrm{q} 34 ; \mathrm{q} 11)$, which reflects the rearrangement of the ABL and BCR genes (2). The Ph chromosome is present in more than $90 \%$ of CML cases (3). In Ph-positive $\mathrm{CML}$, expression of the BCR/ABL chimeric protein $\mathrm{p} 210$ with an increased tyrosine kinase activity is essential for multiple signaling pathways to confer the leukemia phenotype (4).

Complex chromosomal rearrangements involving one or more additional chromosomes have been described in more than $600 \mathrm{CML}$ cases (5). Using conventional cytogenetic analysis, two variant subgroups have traditionally been identified: complex $\mathrm{t}(9 ; 22 ; \mathrm{V})$ where $\mathrm{V}$ represents a third translocation partner chromosome, and simple $\mathrm{t}(9 ; \mathrm{V})$ or $\mathrm{t}(22 ; \mathrm{V})(6)$. Only a few cases exhibit a chromosomal fragment from the third chromosome translocated to the $\operatorname{der}(22) \mathrm{t}(9 ; 22)$ producing

Correspondence to: Dr Walid Al-Achkar, Molecular Biology and Biotechnology Department, Human Genetics Division, Atomic Energy Commission of Syria, P.O. Box 6091, Damascus, Syria E-mail: scientific@aec.org.sy

Keywords: complex variant Philadelphia, BCR/ABL rearrangement, chronic myeloid leukemia, chromosomal aberrations, cytogenetics, fluorescence in situ hybridization a 'masked $\mathrm{Ph}$ ' (7). In the majority of Ph-variant cases, the segment 22q11-qter shifts to a third chromosome, while a part of the third chromosome is located on $9 \mathrm{q} 34$. Deletions on the derivative chromosome 9 occur with a much higher frequency in patients with variant $\mathrm{Ph}$ translocations $(45 \%)$ compared to those with classic $\mathrm{Ph}(17 \%)$ (8).

We present a CML case with a translocated BCR to der(2), involving four different chromosomal breakpoints characterized by molecular cytogenetics.

\section{Materials and methods}

Case report. A 47-year-old female patient was admitted to our Human Genetics Division initially presented with a WBC of 9.66 $10^{9} / 1$ and splenomegaly. Chromosome analysis using banding cytogenetics revealed a karyotype in accordance with the clinical diagnosis of CML in the chronic phase. She was treated with hydroxyurea $(1000 \mathrm{mg} / \mathrm{day})$ for four years and three months. At her initial admission, her hematological parameters were: $85.4 \%$ neutrophils, $7.7 \%$ lymphocytes and $6.9 \%$ immature cells. The platelet count was $372 \times 10^{9} / 1$ and the hemoglobin level was $11.8 \mathrm{~g} / \mathrm{dl}$. She was initially treated with hydroxyurea for 18 months. Then, 33 months later, following hydroxyurea treatment, her WBC was $130.91 \times 10 \% / 1$ (79.8\% neutrophils, $8.5 \%$ lymphocytes and $11.7 \%$ immature cells). The platelet count was $340 \times 10^{9} / 1$, and the hemoglobin level was $11.9 \mathrm{~g} / \mathrm{dl}$.

Banding cytogenetics. Chromosome analyses were performed by the GTG-banding technique according to standard procedures (9). Twenty metaphases, obtained from the unstimulated bone marrow of the patient, were analyzed. Karyotypes were described according to the International System for Human Cytogenetic Nomenclature (10).

Fluorescence in situ hybridization (FISH). FISH was conducted using commercially available probes. LSI BCR/ABL dualcolor dual-fusion translocation probe (Abbott Molecular/Vysis, USA), whole chromosome painting (WCP) probe for chromosomes 1,2 and 22 (MetaSystems, Germany) and $\alpha$ satellite probe (CEP) for chromosome 9 (Abbott Molecular/Vysis) were applied according to the standard method (11). Twenty metaphase spreads were analyzed, using a fluorescence micro- 


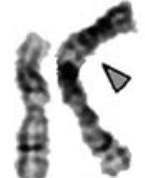

1

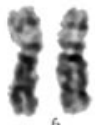

\& 8

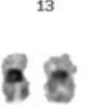

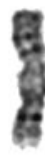

(1)
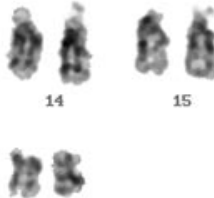

28

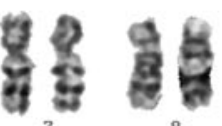

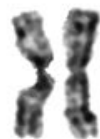

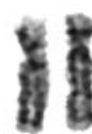

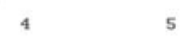

Figure 1. GTG-banding shows a complex karyotype involving two further chromosomes besides chromosomes 9 and 22. Derivative chromosomes are indicated by arrowheads.

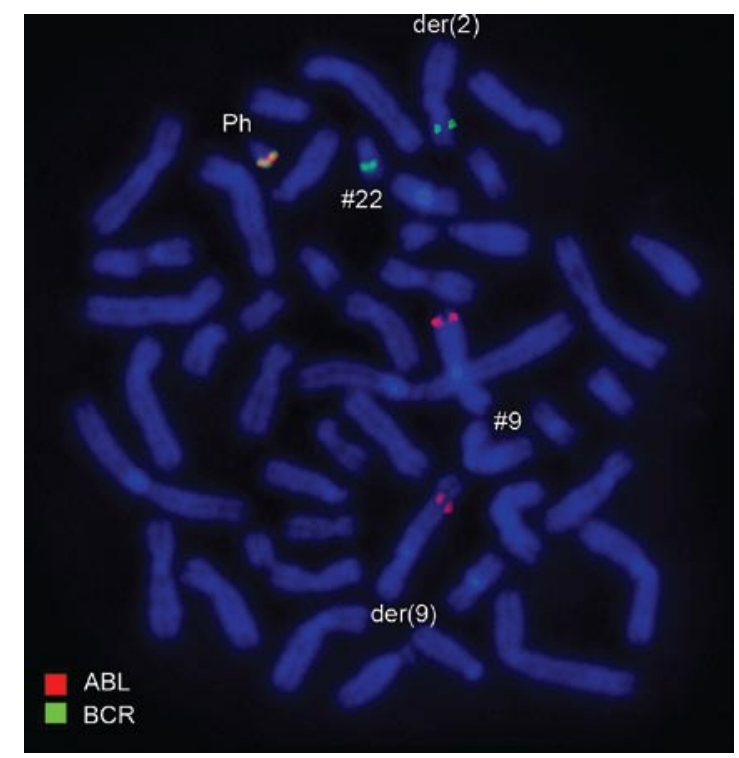

Figure 2. Using probes for BCR (green) and ABL (red), fluorescence in situ hybridization (FISH) confirmed the involvement of chromosome 2 in the rearrangement present in this case. "Chromosome; der, derivative chromosome; Ph, Philadelphia chromosome.

scope (Axio Imager Z1 mot; Zeiss, Germany) equipped with appropriate filter sets to discriminate between a maximum of five fluorochromes and the counterstain 4'6-diamino-2phenylindole. Image capturing and processing were carried out using an Isis image analysis system (MetaSystems).

\section{Results}

Karyotyping was performed at 3 and 10 months after the initiation of hydroxyurea treatment. The same karyotypic changes were noted. A complex karyotype $46, \mathrm{XX}, \mathrm{t}(1 ; 2 ; 9 ; 22)$ was determined in GTG-banding (Fig. 1), and was further studied by molecular cytogenetics (Figs. 2-4). Using a commercially available probe specific for BCR/ABL, dual-color FISH showed that the typical $\mathrm{Ph}$ chromosome with the BCR/ABL translocation was present. However, BCR was translocated to

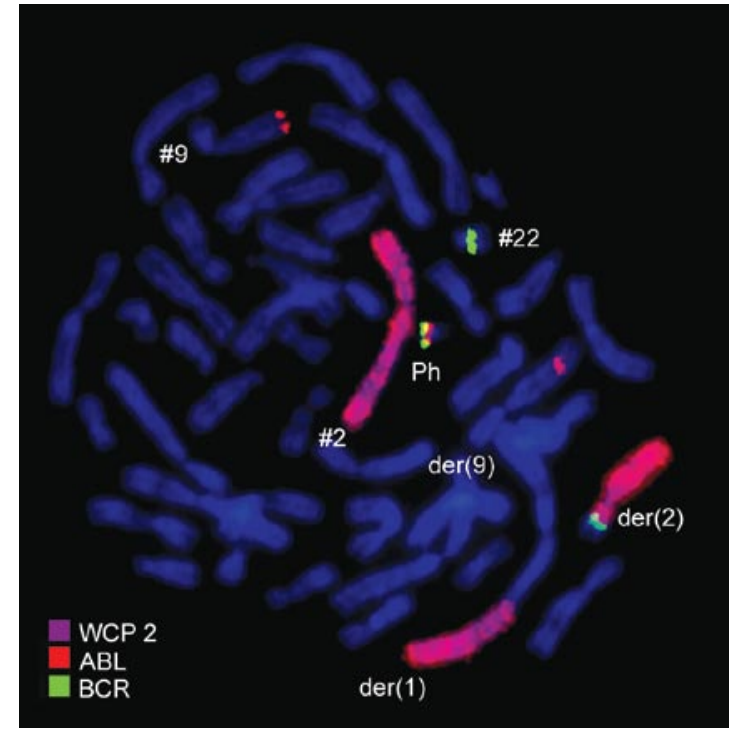

Figure 3. Using probes for BCR (green), ABL (red) and WCP2 (red), fluorescence in situ hybridization (FISH) confirmed the involvement of chromosome 2 in the rearrangement present in this case. ${ }^{\#}$ Chromosome; der, derivative chromosome; $\mathrm{Ph}$, Philadelphia chromosome.

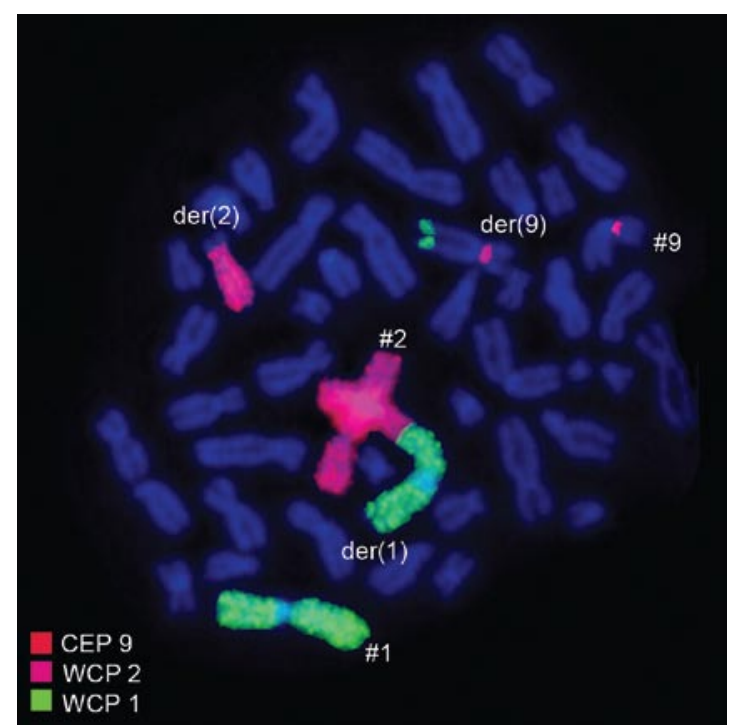

Figure 4. Using probes for WCP1 (green) WCP2 (red) and CEP9 (red), fluorescence in situ hybridization (FISH) confirmed the involvement of chromosome 1 with chromosomes 2 and 9 in this case. ${ }^{\#}$ Chromosome; der, derivative chromosome.

der(2) (Figs. 2 and 3). Another commercially available probe specific for WCP1 + WCP2 + CEP9 confirmed the involvement of chromosome 1 with chromosomes 2 and 9 (Fig. 4). Thus, FISH was performed using probes for the involved chromosomes according to GTG-banding (Figs. 2-4). The result obtained was: 46,XX,t(1;2;9;22)(p32;q21;q34;q11.2).

\section{Discussion}

The present study identified one additional translocation, 46,XX,t(1;2;9;22)(p32;q21;q34;q11.2), in CML-CP. To the best 
of our knowledge, this translocation has never been described in the literature (12).

In $5-8 \%$ of $\mathrm{CML}$ cases, the fusion gene BCR/ABL is the result of a complex translocation (13). At present, it appears that variant translocations can affect any chromosome. However, it has been suggested that the distribution of the breakpoints is non-random, with the chromosomal bands 1p36, 3p21, 5q31, 6p21, 9q22, 10q22, 11q13, 12p13, 17p13, $17 q 21,17 q 25,19 q 13,21 q 22,22 q 12$ and 22q13 being the most susceptible to breakage (5). None of the above-mentioned breakpoints were noted in our study. However, the fusion gene is located on chromosome 22.

Two possible mechanisms for variant translocation formation have been suggested. The first is a single-event rearrangement via the simultaneous breakage of several chromosomes followed by mismatched joining (14). Nacheva et al proposed a classic $\mathrm{Ph}$ translocation followed by a further translocation event between chromosomes 9 and 22 plus a third chromosome (15). The mechanism of the formation of a variant $\mathrm{Ph}$ translocation may have prognostic importance in that a two-event mechanism represents clonal evolution, whereas a variant translocation occurring via a single genomic rearrangement may confer a similar prognosis to the classic $\mathrm{Ph}$ translocation (16).

\section{Acknowledgements}

We thank Dr I. Othman, the Director General of the Atomic Energy Commission of Syria (AECS) and Dr N. Mirali, Head of the Molecular Biology and Biotechnology Department for the support. This study was supported by the Syrian Atomic Energy Commission.

\section{References}

1. Gale RP and Canaani E: An 8-kilobase abl RNA transcript in chronic myelogenous leukemia. Proc Natl Acad Sci USA 81: 5648-5652, 1984.

2. De Klein A, van Kessel AG, Grosveld G, Bartram CR, Hagemeijer A, Bootsma D, Spurr NK, Heisterkamp A, Groffen J and Stephenson JR: A cellular oncogene is translocated to the Philadelphia chromosome in chronic myelogenous leukaemia. Nature 300: 765-777, 1982.
3. Rowley JD: A new consistent chromosomal abnormality in chronic myelogenous leukemia identified by quinacrine fluorescence and Giemsa staining. Nature 243: 290-291, 1973.

4. Lugo T, Pendergast A, Müller A and Witte O: Tyrosine kinase activity and transformation potency of bcr-abl oncogene products. Science 247: 1079-1082, 1990.

5. Johansson B, Fioretos $\mathrm{T}$ and Mitelman F: Cytogenetic and molecular genetic evolution of chronic myeloid leukemia. Acta Haematol 107: 76-94, 2002.

6. Huret JL: Complex translocations, simple variant translocations and $\mathrm{Ph}$-negative cases in chronic myelogenous leukaemia. Hum Genet 85: 565-568, 1990.

7. Hagemeijer A, de Klein A, Godde-Salz E, Turc-Carel C, Smit EME, van Aghtoven AJ and Grosveld GC: Translocation of c-abl to 'masked' Ph in chronic myeloid leukemia. Cancer Genet Cytogenet 18: 95-104, 1985.

8. Reid A, Gribble SM, Huntly BJ, Andrews KM, Campbell L, Grace CD, Wood ME, Green AR and Nacheva EP: Variant Philadelphia translocations in chronic myeloid leukaemia can mimic typical blast crisis chromosome abnormalities or classic $\mathrm{t}(9 ; 22)$ : a report of two cases. Br J Haematol 113: 439-442, 2001.

9. Claussen U, Michel S, Mühlig P, Westermann M, Grummt UW, Kromeyer-Hauschild K and Liehr T: Demystifying chromosome preparation and the implications for the concept of chromosome condensation during mitosis. Cytogenet Genome Res 98: 136-146, 2002.

10. Mitelman F (ed): ISCN An International System for Human Cytogenetic Nomenclature. Karger, Basel, 1995.

11. Al-Achkar W, Wafa A and Nweder MS: A complex translocation $\mathrm{t}(5 ; 9 ; 22)$ in Philadelphia cells involving the short arm of chromosome 5 in a case of chronic myelogenous leukemia. J Exp Clin Cancer Res 26: 411-415, 2007.

12. Mitelman F, Johansson B and Mertens F (eds): http://cgap.nci. nih.gov/chromosomes/Mitelman: Mitelman database on chromosome abberrations in cancer. Accessed Oct. 25, 2007.

13. La Starza R, Testoni N, Lafage-Pochitaloff M, Ruggeri D, Ottaviani E, Perla G, Martelli MF, Marynen P and Mecucci C: Complex variant Philadelphia translocations involving the short arm of chromosome 6 in chronic myeloid leukemia. Haematologica 87: 143-147, 2002.

14. Fitzgerald PH and Morris CM: Complex chromosomal translocations in the Philadelphia chromosome leukemias. Serial translocations or a concerted genomic rearrangement? Cancer Genet Cytogenet 57: 143-151, 1991.

15. Nacheva E, Holloway T, Brown K, Bloxham D and Green AR: Philadelphia-negative chronic myeloid leukaemia: detection by FISH of BCR-ABL fusion gene localized either to chromosome 9 or chromosome 22. Br J Haematol 87: 409-412, 1994.

16. Reid AG, Huntly BJP, Grace C, Green AR and Nacheva EP: Survival implications of molecular heterogeneity in variant Philadelphia-positive chronic myeloid leukaemia. Br J Haematol 121: 419-427, 2003. 